\title{
Increased miR-155-5p expression in dermal mesenchymal stem cells of psoriatic patients: comparing the microRNA expression profile by microarray
}

R.X. Hou ${ }^{1}$, R.F. Liu ${ }^{1}$, X.C. Zhao ${ }^{1}$, Y.R. Jia ${ }^{2}$, P. An ${ }^{1}$, Z.P. Hao ${ }^{3}$, J.Q. Li ${ }^{1}$, X.H. Li ${ }^{1}$, G.H. Yin ${ }^{1}$ and K.M. Zhang ${ }^{1}$

${ }^{1}$ Institute of Dermatology, Taiyuan City Central Hospital, Shanxi Key Laboratory for Immunological Dermatosis, No. 1 Dong San Dao Xiang, Taiyuan, Shanxi, China

${ }^{2}$ Department of Dermatology, Maternal and Child Care Service Centre of Jinzhong City, Jinzhong, Shanxi, China

${ }^{3}$ Department of Dermatology, General Hospital of Taiyuan Iron \& Steel (Group) Co., Ltd., Taiyuan, Shanxi, China

Corresponding author: K.M. Zhang

E-mail: zhangkaiming@sina.com

Genet. Mol. Res. 15 (3): gmr.15038631

Received March 21, 2016

Accepted April 25, 2016

Published September 2, 2016

DOI http://dx.doi.org/10.4238/gmr.15038631

Copyright $(C 2016$ The Authors. This is an open-access article distributed under the terms of the Creative Commons Attribution ShareAlike (CC BY-SA) 4.0 License

ABSTRACT. Mesenchymal stem cells (MSCs) have pleiotropic immuno-modulatory effects and pro-angiogenic ability, leading to the presumption that MSCs may be involved in the pathogenesis of many inflammatory or autoimmune disorders, including psoriasis. In a previous study, we reported the specific gene expression profile of 
dermal MSCs from psoriasis. Inflammation- and angiogenesis-related genes, such as lipopolysaccharide-induced tumor necrosis factor-alpha transcription factor (LITAF), dual-specificity protein phosphatase 1 (DUSP1), vascular endothelial growth factor $\alpha(V E G F \alpha)$, and insulin-like growth factor-binding protein-5 (IGFBP5), are abnormally expressed in psoriatic dermal MSCs. As a key regulator of gene expression, miRNA are involved in a wide variety of biological processes; in fact, several miRNAs have been implicated in the development and progression of inflammatory or autoimmune disorders. In this study, we compared the miRNA expression profiles of dermal MSCs from patients with psoriasis to those in MSCs from normal individuals by microarray, and found that the pro-inflammatory miRNA miR-155 was significantly overexpressed in psoriatic MSCs $(2.44$ fold, $\mathrm{P}<0.001)$. Additionally, the expression of miR-155 target gene TAB2 $(8.47 \pm 1.55$ vs $6.38 \pm 2.10, \mathrm{P}<0.01$, $)$ and the downstream gene $i N O S(5.26 \pm 2.58$ vs $3.73 \pm 1.89, \mathrm{P}<0.05)$ was found to be inhibited in psoriatic dermal MSCs by real-time PCR. Therefore, we speculated that the elevation in miR-155 levels may be an indicator of, or a key regulatory pathway in, the pathogenesis of psoriasis, resulting in functionally impaired dermal MSCs.

Key words: Psoriasis; Mesenchymal stem cells; miR-155; iNOS

\section{INTRODUCTION}

Psoriasis is a common and enigmatic inflammatory skin disease characterized by hyper proliferation of keratinocytes, angiectasis of vascular capillaries in the dermal papilla, and perivascular lymphocyte infiltration. Although not a life-threatening disease, this chronic incurable immune disorder affects the epidermis and joints, and also the endocrine and metabolic systems of patients, significantly impairing their quality of life (Pongpit et al., 2016). The cause of psoriasis remains elusive; however, it is a complex pathological dysfunction involving inflammatory and immune response, and angiogenesis. Overexpression of Th1 and Th17 cytokines, such as interferon (IFN)- $\gamma$, interleukin (IL)-1, IL-17, IL-22, IL-26, and tumor necrosis factor (TNF)- $\alpha$, has been widely accepted as a key pathological factor of psoriasis (Michalak-Stoma et al., 2011).

Several studies have suggested that mesenchymal stem cells (MSCs) exhibit pleiotropic immuno-modulatory effects, including the inhibition of activated $\mathrm{T}$ cell proliferation and increase in $\mathrm{CD}^{+} \mathrm{CD} 25^{+}$regulatory $\mathrm{T}$ cell proportion (Mareschi et al., 2016), suppression of natural killer (NK) cell proliferation (Spaggiari et al., 2006), modulation of cytokine production (Aggarwal and Pittenger, 2005), and inhibition of dendritic cell (DC) maturation (Beyth et al., 2005). The angiogenic capabilities of MSCs, via the expression of vascular endothelial growth factor (VEGF) and other related cytokines, have also been well-documented (Rho et al., 2008; Liu et al., 2011). Given the major pathogenic characteristics of psoriasis, the abnormal inflammatory response and vasodilatation in the dermis, researchers began to focus on dermal MSCs in patients with psoriasis.

We have previously reported that some inflammation- and angiogenesis-related

Genetics and Molecular Research 15 (3): gmr.15038631 
genes, such as $I L-1 \beta, C X C L 14, V E G F \alpha, G A T A-6$, insulin-like growth factor-binding protein-5 (IGFBP5), lipopolysaccharide-induced tumor necrosis factor-alpha transcription factor $(L I T A F)$, and dual-specificity protein phosphatase 1 (DUSP1), are significantly differentially expressed in dermal MSCs from patients with psoriasis (Liu et al., 2013; Hou et al., 2014; Chang et al., 2015). Psoriatic dermal MSCs present an impaired capacity to inhibit T cell proliferation (Liu et al., 2014). Additionally, Campanati et al. (2014) reported that MSCs isolated from psoriatic skin lesions showed high levels of Th1 and Th17 cytokines, such as INF- $\gamma$, TNF- $\alpha$, IL17, IL23A, CXCL2, CXCL5, and IL21. TNF- $\alpha$ inhibitors adalimumab or etanercept have also been shown to suppress VEGF expression in psoriatic dermal MSCs, thereby reducing angiogenesis (Campanati et al., 2012). Collectively, these studies suggested that MSCs may be involved in the pathological process of psoriasis.

MicroRNA (miRNA) are a class of endogenous (non-protein-coding), 19-24 ntlong single-stranded RNA that can regulate gene expression by binding primarily to the 3 '-untranslated regions of specific 'target' mRNA (Bartel, 2009). They are key regulators in a number of biological processes, including development, cell differentiation, angiogenesis, apoptosis, metabolism, and signal transduction (Bartel, 2009). To date, dozens of miRNA, including miR-146a, miR-31, miR-155, and miR-21, have been found to differentially expressed in autoimmune disorders such as systemic lupus erythematosus (SLE), psoriasis, and systemic sclerosis (Deng et al., 2015). However, these studies only analyzed peripheral blood mononuclear cell, T cell, epidermal lesion, keratinocyte, serum, and fibroblast samples, but not MSCs, which are important for immune regulation. Therefore, the relationship between miRNA and MSC function in psoriasis was further investigated by comparing the miRNA expression profile between psoriatic and normal dermal MSCs.

\section{MATERIAL AND METHODS}

\section{Patients and sample collection}

A total of 20 patients with psoriasis ( 12 men and 8 women; age range $=19-52$ years), as diagnosed by a histopathological examination, were recruited to this study. The mean psoriasis area and severity index at the time of sample collection was determined to be $10.6 \pm$ 7.08 (means \pm standard deviation). The control group was composed of 20 healthy volunteers (11 men and 9 women; age range $=21-45$ years) who underwent a recent plastic surgery, from whom redundant skin samples were obtained for this study. Written informed consent was obtained from all participants. The study protocol was approved by the Medical Ethics Committee of the Taiyuan Central Hospital. None of the participants had been prescribed with, or received, oral immunosuppressive agents within at least one month prior to enrolment in this study. Skin tissues $\left(1 \times 1.5 \mathrm{~cm}^{2}\right)$, excised from the participants following infiltration anesthesia, were immediately used for MSC isolation.

\section{Culture and characterization of dermal MSCs}

Dermal MSCs were isolated and expanded as described in previous studies (Hou et al., 2014, Chang et al., 2015). Non-adherent cells were removed after $48 \mathrm{~h}$, and half the medium was changed every 3-4 days. The adherent MSCs were passaged at $80 \%$ confluence.

Genetics and Molecular Research 15 (3): gmr.15038631 
Cell surface markers, such as CD105, CD29, CD44, CD73, CD90, CD45, CD34, and human leukocyte antigen (HLA)-DR (Becton, Dickinson and Company, Franklin Lakes, NJ, USA) were detected via flow cytometry according to a previously described protocol (Liu et al., 2013). The osteogenic and adipogenic in vitro differentiation of MSC cells was performed according to published protocols (Cheng et al., 2011).

\section{Microarray analysis}

Total RNA was isolated from $1 \times 10^{6}$ cultured cells obtained from 12 subjects $(6$ patients and 6 controls) at passage 3 using TRIzol (Invitrogen, Karlsruhe, Germany) and the miRNeasy mini kit (Qiagen, Hilden, Germany) according to manufacturer instructions. One microgram of each sample was labeled using the miRCURYTM $\mathrm{Hy} 3^{\mathrm{TM}} / \mathrm{Hy} 5^{\mathrm{TM}}$ Power labeling kit (Exiqon, Vedbaek, Denmark) according to the manufacturer protocols. The Hy $3^{\mathrm{TM}}$-labeled samples were then hybridized onto a miRCURY ${ }^{\mathrm{TM}}$ LNA array (v.16.0) (Exiqon) according to the array manual. The $\mathrm{Hy}^{\mathrm{TM}}$-labeled samples were dissolved in $25 \mu \mathrm{L}$ hybridization buffer, denatured for $2 \mathrm{~min}$ at $95^{\circ} \mathrm{C}$, incubated on ice for $2 \mathrm{~min}$, and subsequently hybridized on to the microarray for $16-20 \mathrm{~h}$ at $56^{\circ} \mathrm{C}$ in a 12-Bay Hybridization System (Nimblegen Systems, Inc., Madison, WI, USA). The slides were washed several times and finally dried by centrifugation at $400 \mathrm{~g}$ for $5 \mathrm{~min}$. The slides were then scanned using the Axon GenePix 4000B microarray scanner (Axon Instruments, Foster City, CA, USA).

\section{Data analysis}

The scanned images were then imported into the GenePix Pro 6.0 software (Axon) for grid alignment and data extraction. Averages of the replicated miRNA were taken; miRNA with intensities $\geq 50$ were chosen in all samples to calculate a normalization factor. The data was normalized using the median normalization method, and significantly and differentially expressed miRNA were identified through Volcano Plot filtering with a threshold fold change $\geq 2$ or $\leq 0.5$ and $P$ value $\leq 0.05$. Hierarchical clustering was performed using the MEV software (v4.6, TIGR. http://www.tm4.org/, TM4, Boston, MA, USA).

\section{Real-time PCR}

Total RNA was isolated from all 40 samples using TRIzol and miRNeasy mini kit (Qiagen) and used in real-time PCR analysis. First-strand complementary DNA (cDNA) was synthesized using $500 \mathrm{ng}$ total RNA, $5 \mathrm{nmol}$ dNTP, $0.3 \mathrm{nmol}$ reverse transcriptase (RT) primers (Table 1), $2 \mu \mathrm{L}$ 10X RT buffer (Epicentre Illumina, Inc., Madison, WI, USA), 12 U RNAse inhibitor (Epicentre), and $20 \mathrm{U}$ MMLV reverse transcriptase (Epicentre) in a total volume of 20 $\mu \mathrm{L}$. The RT reaction was performed at $16^{\circ} \mathrm{C}$ for $30 \mathrm{~min}, 42^{\circ} \mathrm{C}$ for $40 \mathrm{~min}$, and $85^{\circ} \mathrm{C}$ for $5 \mathrm{~min}$.

PCR amplification was performed in a $25 \mu \mathrm{L}$ system containing $2 \mu \mathrm{g}$ cDNA, $2.5 \mu \mathrm{L}$ 10X PCR buffer, $0.01 \mathrm{nmol}$ each primer (Table 2), $0.5 \mu \mathrm{L} 2 \mathrm{X}$ ROX reference dye, and $0.25 \mathrm{X}$ Sybergreen I. The thermal cycling conditions were set as follows: pre-denaturation at $95^{\circ} \mathrm{C}$ for $5 \mathrm{~min}$ and 40 cycles at $95^{\circ} \mathrm{C}$ for $10 \mathrm{~s}, 60^{\circ} \mathrm{C}$ for $20 \mathrm{~s}, 72^{\circ} \mathrm{C}$ for $20 \mathrm{~s}$, and $78^{\circ} \mathrm{C}$ for $20 \mathrm{~s}$. The $U 6$ RNA was applied as an internal reference, and differences in gene expression between the two groups were analyzed using the $2^{-\Delta \Delta \mathrm{Ct}}$ method (Livak and Schmittgen, 2001). The $t$-test, based

Genetics and Molecular Research 15 (3): gmr.15038631 
on $\Delta \mathrm{Ct}$, was performed to identify significant differences, and $\mathrm{P}$ values $\leq 0.05$ were considered to be statistically significant.

Table 1. Reverse transcriptase (RT) primer sequence of cDNA synthesis.

\begin{tabular}{l|l}
\hline Genes & RT primer \\
\hline$U 6$ & 5'CGCTTCACGAATTTGCGTGTCAT3' \\
\hline$h s a-m i R-381$ & 5'GTCGTATCCAGTGCGTGTCGTGGAGTCGGCAATTGCACTGGATACGACACAGAG3' \\
\hline$h s a-m i R-525-5 p$ & 5'GTCGTATCCAGTGCGTGTCGTGGAGTCGGCAATTGCACTGGATACGACAGAAAG3' \\
\hline$h s a-m i R-299-3 p$ & 5'GTCGTATCCAGTGCGTGTCGTGGAGTCGGCAATTGCACTGGATACGACAAGCGG3' \\
\hline$h s a-m i R-155-5 p$ & 5'GTCGTATCCAGTGCGTGTCGTGGAGTCGGCAATTGCACTGGATACGACACCCCTA3' \\
\hline$h s a-m i R-337-3 p$ & 5'GTCGTATCCAGTGCGTGTCGTGGAGTCGGCAATTGCACTGGATACGACGAAGAAA3' \\
\hline$h s a-m i R-654-3 p$ & 5'GTCGTATCCAGTGCGTGTCGTGGAGTCGGCAATTGCACTGGATACGACAAGGTGA3' \\
\hline$h s a-m i R-423-5 p$ & 5'GTCGTATCCAGTGCGTGTCGTGGAGTCGGCAATTGCACTGGATACGACAAAGTCT3' \\
\hline
\end{tabular}

Table 2. Primers used for polymerase chain reaction.

\begin{tabular}{|c|c|c|c|}
\hline Genes & Primer sequence & Annealing temperature $\left({ }^{\circ} \mathrm{C}\right)$ & Product length (bp) \\
\hline U6 & $\begin{array}{l}\text { F: 5'GCTTCGGCAGCACATATACTAAAAT3' } \\
\text { R: 5'CGCTTCACGAATTTGCGTGTCAT3' }\end{array}$ & 60 & 89 \\
\hline hsa-miR-381 & $\begin{array}{l}\text { GSP: 5'GCCTATACAAGGGCAAGC3' } \\
\text { R: 5'GTGCGTGTCGTGGAGTCG 3' }\end{array}$ & 60 & 65 \\
\hline hsa-miR-525-5p & $\begin{array}{l}\text { GSP: 5'GCTCCAGAGGGATGCA3' } \\
\text { R: 5'GTGCGTGTCGTGGAGTCG 3' }\end{array}$ & 60 & 62 \\
\hline hsa-miR-299-3p & $\begin{array}{l}\text { GSP: 5'GGGTATGTGGGATGGTAAA3' } \\
\text { R: 5'CAGTGCGTGTCGTGGAGT3' }\end{array}$ & 60 & 64 \\
\hline hsa-miR-155-5p & $\begin{array}{l}\text { GSP: 5'GGGGTAATGCTAATCGTGA3' } \\
\text { R: 5'CAGTGCGTGTCGTGGAG3' }\end{array}$ & 60 & 66 \\
\hline hsa-miR-337-5p & $\begin{array}{l}\text { GSP: 5'GGGTCTCCTATATGATGCCT3' } \\
\text { R: 5'CAGTGCGTGTCGTGGAG3' }\end{array}$ & 60 & 66 \\
\hline hsa-miR-654-3p & $\begin{array}{l}\text { GSP: 5'GGGATGTCTGCTGACCA3' } \\
\text { R: 5'CAGTGCGTGTCGTGGA3' }\end{array}$ & 60 & 64 \\
\hline$h s a-m i R-423-5 p$ & $\begin{array}{l}\text { GSP: 5'TGAGGGGCAGAGAGCG3' } \\
\text { R: 5'CAGTGCGTGTCGTGGAGT3' }\end{array}$ & 60 & 61 \\
\hline TAB2 & $\begin{array}{l}\text { F: 5'GCAGCAAAGGAACATCTAGCC3' } \\
\text { R: 5'TGGACTGTTAAGTACAGGTGGA3' }\end{array}$ & 61 & 146 \\
\hline iNOS & $\begin{array}{l}\text { F: 5'AGGGACAAGCCTACCCCTC3' } \\
\text { R: 5'CTCATCTCCCGTCAGTTGGT3' }\end{array}$ & 61 & 168 \\
\hline
\end{tabular}

GSP: Specific forward (F) primer of each miRNA. R: reverse primer.

\section{RESULTS}

\section{Identification of cultured dermal MSCs}

As reported in our previously published data (Hou et al., 2014), the cells cultured in this study were adherent, CD105', CD29+, CD44 ${ }^{+}, \mathrm{CD}^{+} 3^{+}, \mathrm{CD} 90^{+}, \mathrm{CD} 45^{-}, \mathrm{CD} 34-\mathrm{HLA}-\mathrm{DR}$, and presented a typical fibroblast flat triangular or spindle morphology, and could be induced to differentiate into both osteoblasts and adipocytes.

\section{Differential miRNA expression in psoriatic and normal dermal MSCs}

At present, the expression and function of miRNA in MSCs remains largely unknown. In order to confirm the possible role of miRNA expressed by dermal MSCs in the pathogenesis of psoriasis, we performed a comprehensive analysis of all human miRNA registered in mirBase 8.0 in dermal MSCs obtained from patients with psoriasis $(\mathrm{N}=6)$ and normal controls $(\mathrm{N}=$ 
6). Unsupervised hierarchical cluster analysis of the microarray data revealed that miRNA are expressed in a non-random manner in both patients and normal controls (Figure 1a). Volcano Plot filtering of the data identified 13 miRNA that were differentially expressed ( 5 up-regulated and 8 down-regulated) between psoriatic and healthy dermal MSCs (Figure 1b and Table 3). The microarray data were deposited under NCBI GEO GSE42633.
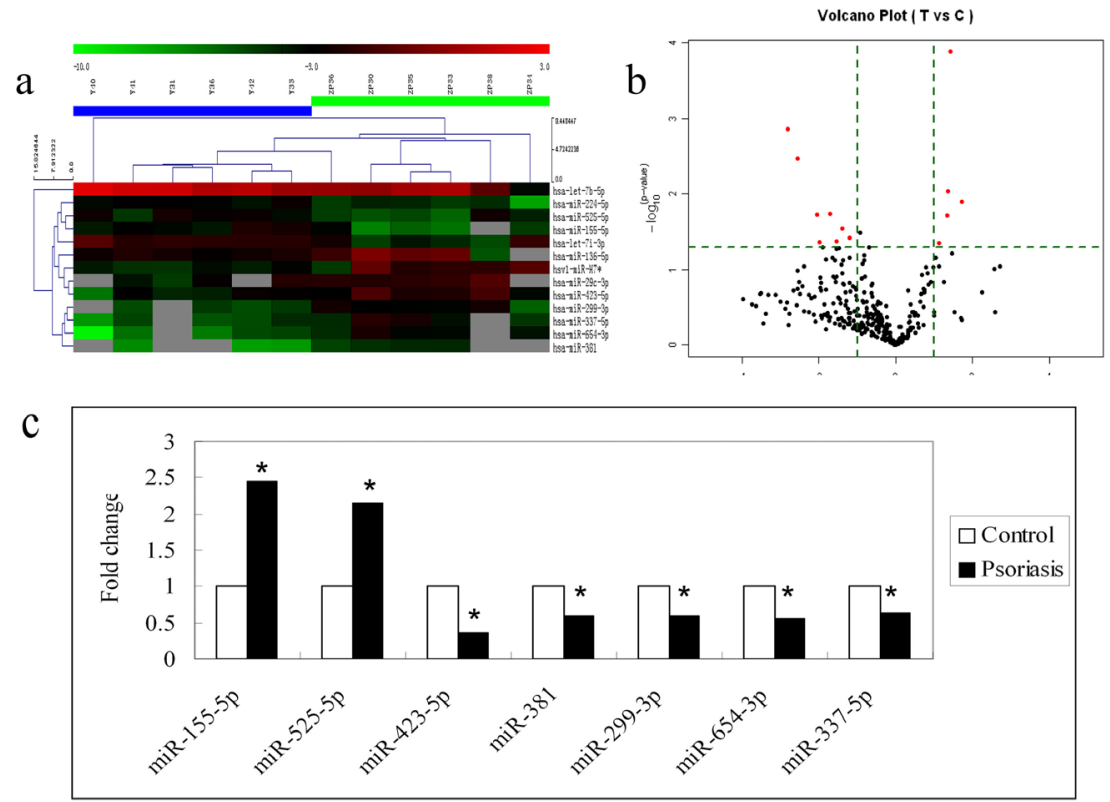

Figure 1. Differential microRNA expression profile between derma Mesenchymal Stem Cells (MSCs) from psoriatic and normal individuals. a. Hierarchical clustering, Y: psoriasis patients and ZP: normal controls. b. Volcano plot constructed using fold-change values and $\mathrm{P}$ values. The threshold values for fold change were set at $\geq 2$ or $\leq 0.5$ (outside the vertical lines) and $\mathrm{P}$ value $\leq 0.05$ (above the horizontal line); red points in the plots represent the significant differentially expressed miRNA. c. Fold change of several miRNA confirmed by real-time PCR (psoriasis $v s$ control), $* \mathrm{P} \leq 0.001$.

Table 3. Differently expressed microRNA between dermal mesenchymal stem cells (MSCs) from psoriasis and normal patients as identified by microarray and real-time polymerase chain reaction (PCR).

\begin{tabular}{|c|c|c|c|}
\hline \multirow[t]{2}{*}{ Name } & \multicolumn{2}{|c|}{ Microarray } & \multirow{2}{*}{$\frac{\text { Real-time PCR }}{2^{-\Delta \Delta C t}}$} \\
\hline & Fold change & $\mathrm{P}$ value & \\
\hline hsa-let-7b-5p & 2.55 & 0.009 & - \\
\hline hsa-miR-155-5p & 3.28 & 0.012 & 2.44 \\
\hline hsa-let-7i-3p & 2.51 & 0.019 & - \\
\hline$h s a-m i R-224-5 p$ & 2.67 & 0.0001 & - \\
\hline$h s a-m i R-525-5 p$ & 2.18 & 0.044 & 2.16 \\
\hline$h s a-m i R-423-5 p$ & 0.38 & 0.028 & 0.36 \\
\hline hsa-miR-136-5p & 0.34 & 0.043 & - \\
\hline$h s v 1-m i R-H 7 *$ & 0.24 & 0.019 & - \\
\hline hsa-miR-381 & 0.14 & 0.001 & 0.60 \\
\hline hsa-miR-299-3p & 0.30 & 0.018 & 0.60 \\
\hline$h s a-m i R-29 c-3 p$ & 0.43 & 0.038 & - \\
\hline hsa-miR-654-3p & 0.17 & 0.003 & 0.55 \\
\hline$h s a-m i R-337-5 p$ & 0.25 & 0.044 & 0.63 \\
\hline
\end{tabular}

Genetics and Molecular Research 15 (3): gmr.15038631 
The results obtained by microarray profiling of $m i R-155-5 p$ (NR_030784.1), $m i R$ 525-5p (NR_030192.1), miR-381 (NR_029873.1), miR-299-3p (NR_029841.1), miR337-5p (NR_029889.1), miR-654-3p (NR_030390.1), and miR-423-5p (NR_029945.1) expression were confirmed by semi-quantitative real-time PCR analysis, using U6 RNA as the control, as well as primers designed to amplify the mature, biologically active form of these miRNA. In accordance with the microarray data, semi-quantitative real-time PCR revealed an increase in miR-155-5p (2.44 fold, $\mathrm{P}<0.001)$ and $m i R-525-5 p$ (2.16 fold, $\mathrm{P}<$ $0.001)$ expression and a decrease in the expression of $m i R-381$ ( 0.6 fold, $\mathrm{P}<0.001), m i R$ 299-3p (0.6 fold, $\mathrm{P}<0.001$ ), miR-337-5p (0.63 fold, $\mathrm{P}<0.001$ ), miR-654-3p (0.55 fold, $\mathrm{P}$ $<0.001)$, and $m i R-423-5 p(0.36$ fold, $\mathrm{P}<0.001)$ in patient samples compared to the control samples (Figure 1c and Table 3).

\section{GO analysis of target genes of the differently expressed miRNA}

miRNA function is generally characterized by the genes they regulate; therefore, the functions of differentially expressed miRNA in psoriasis were characterized using miRWalk, a database designed to predict and validate miRNA target genes. Thus, we identified the validated target genes of 7 differently expressed miRNA (Table S1).

Of the 7 analyzed miRNA, we found a possible correlation between $m i R-155-5 p$ and the pathogenesis of psoriasis. miRWalk listed 733 validated target genes of $m i R-155$ $5 p$, most of which played a role in important biological processes such as the regulation of cell proliferation, apoptosis, cytokine secretion, immune cell activation/chemotaxis, angiogenesis, and signal transduction.

\section{Expression of $m i R-155$ target gene and related cytokines in psoriatic dermal MSCs}

The results of GO analysis indicated that $m i R-155$ could play a role in the immune/ inflammatory response in psoriatic patients. miR-155 expression is induced in MSCs by inflammatory cytokines such as IFN- $\gamma$, TNF- $\alpha$, LPS, or IL-1, which in turn inhibits the expression of inducible nitric oxide synthase (iNOS) by targeting TAK1-binding protein 2 (TAB2), a signaling protein that connects inflammatory cytokines to the NF- $\kappa \mathrm{B}$ pathway (Xu et al., 2013). Additionally, other inflammatory cytokines such as TNF- $\alpha$, IL-12, and IFN- $\gamma$ can be regulated by $m i R-155$. Therefore, in this study, we detected the expression of TAB2 and iNOS using real-time PCR and compared the cytokine expression between the two sample groups using a cytokine array. As shown in Table 4, the expressions of both TAB2 and $i N O S$ were low in psoriatic dermal MSCs. An additional ELISA analysis, performed to identify differentially expressed inflammatory cytokines between normal and psoriatic dermal MSCs, revealed that, while CCL-1, IGF-2, and IGFBP-1 levels were significantly up-regulated in the test group ( $\mathrm{P} \leq 0.05)$, those of TNF- $\alpha$, IL-12, IFN- $\gamma$, MCP-1, and IL-6 (reported to be influenced by miR-155 in other cell types) were not significantly different between the two sample groups $(\mathrm{P} \geq 0.05)$. In fact, the two groups showed similar levels of transforming growth factor (TGF)- $\beta$ and IL-10 (P $\geq 0.05)$ (Figure 2 and Table 4).

Genetics and Molecular Research 15 (3): gmr.15038631 


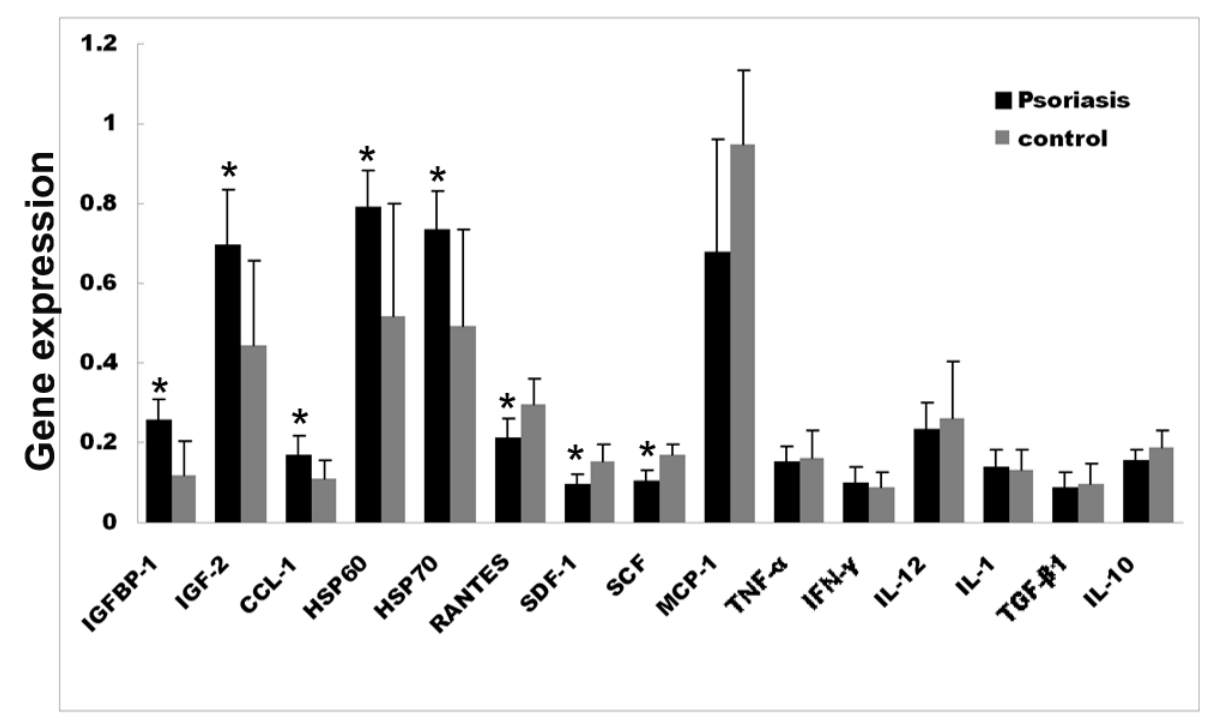

Figure 2. Cytokine expression in psoriatic and normal dermal MSCs. $* \mathrm{P} \leq 0.05$.

Table 4. miR-155 target genes and related cytokines in psoriatic dermal mesenchymal stem cells (MSCs).

\begin{tabular}{l|c|c|c|c}
\hline Name & Psoriasis & Control & Fold change & P value \\
\hline$T A B 2^{a}$ & $8.47 \pm 1.55^{\mathrm{b}}$ & $6.38 \pm 2.10^{\mathrm{b}}$ & $0^{\mathrm{b}}$ & $0.23^{\mathrm{c}}$ \\
\hline$i N O S^{a}$ & $5.26 \pm 2.58^{\mathrm{b}}$ & $3.73 \pm 1.89^{\mathrm{b}}$ & $0.35^{\mathrm{c}}$ & 0.0254 \\
\hline$I G F B P-1$ & $0.26 \pm 0.05$ & $0.12 \pm 0.09$ & 2.18 & 0.0079 \\
\hline$I G F-2$ & $0.69 \pm 0.14$ & $0.44 \pm 0.21$ & 1.57 & 0.0363 \\
\hline$C C L-1$ & $0.17 \pm 0.05$ & $0.11 \pm 0.05$ & 1.57 & 0.0489 \\
\hline$H S P 60$ & $0.79 \pm 0.09$ & $0.52 \pm 0.28$ & 1.54 & 0.0451 \\
\hline$H S P 70$ & $0.74 \pm 0.09$ & $0.49 \pm 0.24$ & 0.71 & 0.0252 \\
\hline$R A N T E S$ & $0.21 \pm 0.05$ & $0.30 \pm 0.06$ & 0.62 & 0.0242 \\
\hline$S D F-1$ & $0.09 \pm 0.03$ & $0.15 \pm 0.05$ & 0.62 & 0.0023 \\
\hline$S C F$ & $0.10 \pm 0.03$ & $0.17 \pm 0.03$ & 0.72 & 0.0823 \\
\hline$M C P-1$ & $0.68 \pm 0.29$ & $0.95 \pm 0.19$ & 0.95 & 0.17 \\
\hline$T N F-\alpha$ & $0.15 \pm 0.04$ & $0.16 \pm 0.07$ & 0.91 & 0.7717 \\
\hline$I F N-\gamma$ & $0.10 \pm 0.04$ & $0.09 \pm 0.04$ & 1.07 & 0.7359 \\
\hline$I L-12$ & $0.24 \pm 0.07$ & $0.26 \pm 0.14$ & 0.94 & 0.8409 \\
\hline$I L-1$ & $0.14 \pm 0.04$ & $0.13 \pm 0.05$ & 0.83 & 0.1392 \\
\hline$I L-10$ & $0.09 \pm 0.04$ & $0.09 \pm 0.05$ & $0.19 \pm 0.04$ & \\
\hline
\end{tabular}

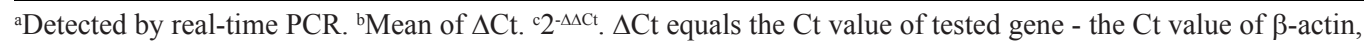
$\Delta \Delta \mathrm{Ct}$ equals the average $\Delta \mathrm{Ct}$ of psoriasis - the $\Delta \mathrm{Ct}$ of control.

\section{DISCUSSION}

Psoriasis is a chronic recurring inflammatory disorder that clinically manifests as well-demarcated red, scaly plaques with intense pruritus. It is commonly considered as an immunological disease because of the marked activation of $\mathrm{CD}^{+} \mathrm{T}$ cells and the overexpression of Th1 and Th17 inflammatory cytokines, such as IFN- $\gamma$, IL-1, IL-17, IL-22, IL-26, and TNF- $\alpha$ (Prinz, 2003; Michalak-Stoma et al., 2011). MSCs have been extensively studied both in vitro 
and in vivo for their pro-angiogenesis ability and immunomodulatory effects. Although the exact mechanism of MSCs remains to be elucidated, soluble cytokines, such as TGF- $\beta$ (Groh et al., 2005; Nemeth et al., 2010), IL-10 (Beyth et al., 2005), prostaglandin E2 (Aggarwal and Pittenger, 2005), nitric oxide (NO), and iNOS (Ren et al., 2008), are reportedly involved in these functions. In our previous study, we observed that inflammation and angiogenesisrelated genes, such as $I L-1 \beta, C X C L 14, V E G F-\alpha, G A T A-6$, and IGFBP5, were differentially expressed in dermal MSCs of patients with psoriasis (Hou et al., 2014). Therefore, researchers have attempted to identify the role of MSCs in the pathogenesis of psoriasis. For example, Campanati et al. (2012) reported that dermal MSCs participated in psoriatic pathogenesis via the promotion of angiogenesis and suppression of antioxidant capacity.

miRNA are key regulators of a wide variety of biological processes, including cell development and differentiation, angiogenesis, apoptosis, metabolism, and signal transduction (Ambros, 2004). To date, dozens of miRNA have been implicated in diseases characterized by abnormal immune response, such as cancers and inflammatory or autoimmune disorders such as psoriasis (Sonkoly et al., 2007; O'Connell et al., 2010; Tili et al., 2011; Deng et al., 2015). In this study, dermal MSCs, immune regulatory cells located in the dermis, were analyzed for differentially expressed miRNA and identified 13 (5 up-regulated and 8 down-regulated) that were significant. Therefore, this study describes, for the first time, the miRNA expression profiles of psoriatic dermal MSCs. Furthermore, functional analyses of these genes revealed that increased $m i R-155-5 p$ expression may be of importance in psoriasis development.

Inflammatory cytokine or antigen activation induces an increase in the miR-155 expression by immunocytes, such as MSCs, DCs, macrophages, and NK cells. This results in impaired immunosuppression capacity, DC apoptosis, and increased inflammatory cytokine and chemokine production (Tili et al., 2007; Lu et al., 2011; Tili et al., 2011; Trotta et al., 2012). Previous studies have reported the presence of high amounts of miR-155 in various types of cancer, as well as in autoimmune diseases such as SLE (Divekar et al., 2011), but not in psoriasis.

In this study, we detected elevated miR-155-5p expression in dermal MSCs derived from patients with psoriasis. As reported by Xu et al. (2013), miR-155 expression in MSCs can be induced by inflammatory cytokines, such as IFN- $\gamma$, TNF- $\alpha$, or IL-1 (that are significantly upregulated in psoriasis). Therefore, the elevated miR-155 expression in psoriatic dermal MSCs may be a result of dysregulated immune response in patients with psoriasis. $m i R$ 155 negatively regulates the iNOS expression by inhibiting its target gene TAB2 (Xu et al., 2013). iNOS is an inflammation-induced enzyme that plays an important role in NO synthesis, inflammatory cytokine secretion, and angiogenesis. Inhibition of iNOS expression in MSCs leads to a decrease in the immunosuppressive capacity of these cells (Xu et al., 2013). In a previous study, we had reported that lymphocyte inhibition of dermal MSCs was impaired in patients with psoriasis (Liu et al., 2014). These studies indicated that elevated miR-155 levels and decreased iNOS expression in psoriatic MSCs may, to a large extent, influence the cytokine expression and immunoregulatory function of MSCs. The results of this study show that the expression of the miR-155 target gene TAB2, as well as that of iNOS, was low in psoriatic dermal MSCs; on the other hand, the expression of TGF- $\beta$ and IL-10, factors that are important for MSC function, did not differ significantly between the two sample groups. This indicated that MSC dysfunction in patients with psoriasis was induced by miR-155 and mediated by iNOS, and not TGF- $\beta$ and IL-10. Additionally, the expression of cytokines such as TNF- $\alpha$, IL-12, IFN- $\gamma$, MCP-1, and IL-6, previously reported to be influenced by miR- 
155 in other cell types, was not significantly different between the two sample groups. This suggested that the effect of miR-155 on MSCs may differ significantly from its influence on other immune cells.

In conclusion, the characteristic miRNA expression profile of MSCs in the psoriatic dermis was identified in this study. Abnormal inflammatory cytokine expression in psoriatic lesions may induce an increase in the miR-155 expression in MSCs, subsequently impairing its immune-suppression ability by inhibiting TAB2 and iNOS expression. Therefore, we concluded that miR-155-induced dysfunctional dermal MSCs may participate in the pathogenesis of psoriasis, as they cannot sufficiently suppress the inflammatory response in psoriatic lesions. These results could pave the way for the development of a potential therapy for psoriasis by targeting miR-155 in dermal MSCs.

\section{Conflicts of interest}

The authors declare no conflict of interest.

\section{ACKNOWLEDGMENTS}

Research supported by the National Nature Science Foundation of China (grant \#81271768 and \#81472888) and the Nature Science Foundation of Shanxi Province (\#2012011045-2 and \#2014011046-4). The authors would also like to sincerely thank all the patients and volunteers for their participation in this study.

\section{REFERENCES}

Aggarwal S and Pittenger MF (2005). Human mesenchymal stem cells modulate allogeneic immune cell responses. Blood 105: 1815-1822. http://dx.doi.org/10.1182/blood-2004-04-1559

Ambros V (2004). The functions of animal microRNAs. Nature 431: 350-355.

Bartel DP (2009). MicroRNAs: target recognition and regulatory functions. Cell 136: 215-233. http://dx.doi.org/10.1016/j. cell.2009.01.002

Beyth S, Borovsky Z, Mevorach D, Liebergall M, et al. (2005). Human mesenchymal stem cells alter antigenpresenting cell maturation and induce T-cell unresponsiveness. Blood 105: 2214-2219. http://dx.doi.org/10.1182/ blood-2004-07-2921

Campanati A, Orciani M, Consales V, Lazzarini R, et al. (2014). Characterization and profiling of immunomodulatory genes in resident mesenchymal stem cells reflect the Th1-Th17/Th2 imbalance of psoriasis. Arch. Dermatol. Res. 306: 915-920. http://dx.doi.org/10.1007/s00403-014-1493-3

Campanati A, Orciani M, Gorbi S, Di Primio R, et al. (2012). Effect of biologic therapies targeting tumour necrosis factor- $\alpha$ on cutaneous mesenchymal stem cells in psoriasis. Br. J. Dermatol. 167: 68-76. http://dx.doi.org/10.1111/ j.1365-2133.2012.10900.x

Chang WJ, Niu XP, Hou RX, Li JQ, et al. (2015): LITAF, HHEX, and DSUP1 expression in mesenchymal stem cells from patients with psoriasis. Gen. Mol. Res. 14: 15793-15801. http://dx.doi.org/10.4238/2015.December.1.31

Cheng H, Qiu L, Zhang H, Cheng M, et al. (2011). Arsenic trioxide promotes senescence and regulates the balance of adipogenic and osteogenic differentiation in human mesenchymal stem cells. Acta Biochim. Biophys. Sin. 43: 204209. http://dx.doi.org/10.1093/abbs/gmq130

Deng X, Su Y, Wu H, Wu R, et al. (2015). The role of microRNAs in autoimmune diseases with skin involvement. Scand. J. Immunol. 81: 153-165. http://dx.doi.org/10.1111/sji.12261

Divekar AA, Dubey S, Gangalum PR and Singh RR (2011). Dicer insufficiency and microRNA-155 overexpression in lupus regulatory T cells: an apparent paradox in the setting of an inflammatory milieu. J. Immunol. 186: 924-930. http://dx.doi.org/10.4049/jimmunol.1002218

Groh ME, Maitra B, Szekely E and Koc ON (2005). Human mesenchymal stem cells require monocyte-mediated activation

Genetics and Molecular Research 15 (3): gmr.15038631 
to suppress alloreactive T cells. Exp. Hematol. 33:928-934.

Hou R, Yan H, Niu X, Chang W, et al. (2014). Gene expression profile of dermal mesenchymal stem cells from patients with psoriasis. J. Eur. Acad. Dermatol. 28: 1782-1791. http://dx.doi.org/10.1111/jdv.12420

Liu R, Wang Y, Zhao X, Yang Y, et al. (2014). Lymphocyte inhibition is compromised in mesenchymal stem cells from psoriatic skin. Eur. J. Dermatol. 24: 560-567.

Liu R, Yang Y, Yan X and Zhang K (2013). Abnormalities in cytokine secretion from mesenchymal stem cells in psoriatic skin lesions. Eur. J. Dermatol. 23: 600-607.

Liu Y, Han ZP, Zhang SS, Jing YY, et al. (2011). Effects of inflammatory factors on mesenchymal stem cells and their role in the promotion of tumor angiogenesis in colon cancer. J. Biol. Chem. 286: 25007-25015. http://dx.doi.org/10.1074/ jbc.M110.213108

Livak KJ and Schmittgen TD (2001). Analysis of relative gene expression data using real-time quantitative PCR and the 2(-Delta Delta C(T)) method. Methods 25: 402-408. http://dx.doi.org/10.1006/meth.2001.1262

Lu C, Huang X, Zhang X, Roensch K, et al. (2011). miR-221 and miR-155 regulate human dendritic cell development, apoptosis, and IL-12 production through targeting of $p 27^{\mathrm{kipl}}$, KPC1, and SOCS-1. Blood 16: 4293-4303. http://dx.doi. org/10.1182/blood-2010-12-322503

Mareschi K, Castiglia S, Sanavio F, Rustichelli D, et al. (2016). Immunoregulatory effects on T lymphocytes by human mesenchymal stromal cells isolated from bone marrow, amniotic fluid, and placenta. Exp. Hematol. 44: 138-150. http://dx.doi.org/10.1016/j.exphem.2015.10.009

Michalak-Stoma A, Pietrzak A, Szepietowski JC, Zalewska-Janowska A, et al. (2011). Cytokine network in psoriasis revisited. Eur. Cytokine Netw. 22: 160-168.

Nemeth K, Keane-Myers A, Brown JM, Metcalfe DD, et al. (2010). Bone marrow stromal cells use TGF- $\beta$ to suppress allergic responses in a mouse model of ragweed-induced asthma. PNAS USA 107: 5652-5657. http://dx.doi. org/10.1073/pnas.0910720107

O'Connell RM, Rao DS, Chaudhuri AA and Baltimore D (2010). Physiological and pathological roles for microRNAs in the immune system. Nat. Rev. Immunol. 10: 111-122. http://dx.doi.org/10.1038/nri2708

Pongpit J, Porntharukchareon S, Kaewduang P, Promson K, et al. (2016). Liver stiffness measurement in psoriasis: do metabolic or disease factors play the important role? Biomed. Res. Int. [Epub ahead of print]. http://dx.doi. org/10.1155/2016/7963972

Prinz JC (2003). The role of T cells in psoriasis. J. Eur. Acad. Dermatol. Venereol. 17: 257-270. http://dx.doi.org/10.1046/ j.1468-3083.2003.00720.x

Ren G, Zhang L, Zhao X, Xu G, et al. (2008). Mesenchymal stem cell-mediated immunosuppression occurs via concerted action of chemokines and nitric oxide. Cell Stem Cell 2: 141-150. http://dx.doi.org/10.1016/j.stem.2007.11.014

Rho SB, Dong SM, Kang S, Seo SS, et al. (2008). Insulin-like growth factor-binding protein-5 (IGFBP-5) acts as a tumor suppressor by inhibiting angiogenesis. Carcinogenesis 29: 2106-2111. http://dx.doi.org/10.1093/carcin/bgn206

Sonkoly E, Wei T, Janson PC, Sääf A, et al. (2007). MicroRNAs: Novel regulators involved in the pathogenesis of psoriasis? PloS One 2: e610. http://dx.doi.org/10.1371/journal.pone.0000610

Spaggiari GM, Capobianco A, Becchetti S, Mingari MC, et al. (2006). Mesenchymal stem cell-natural killer cell interactions: evidence that activated NK cells are capable of killing MSCs, whereas MSCs can inhibit IL-2-induced NK-cell proliferation. Blood 107: 1484-1490. http://dx.doi.org/10.1182/blood-2005-07-2775

Tili E, Michaille JJ, Cimino A, Costinean S, et al. (2007). Modulation of miR-155 and miR-125b levels following lipopolysaccharide/TNF-alpha stimulation and their possible roles in regulating the response to endotoxin shock. $J$. Immunol. 179: 5082-5089. http://dx.doi.org/10.4049/jimmunol.179.8.5082

Tili E, Michaille JJ, Wernicke D, Alder H, et al. (2011). Mutator activity induced by microRNA-155 (miR-155) links inflammation and cancer. PNAS 108: 4908-4913. http://dx.doi.org/10.1073/pnas.1101795108

Trotta R, Chen L, Ciarlariello D, Josyula S, et al. (2012). miR-155 regulates IFN- $\gamma$ production in natural killer cells. Blood 15: 3478-3485. http://dx.doi.org/10.1182/blood-2011-12-398099

Xu C, Ren G, Cao G, Chen Q, et al. (2013). miR-155 Regulates immune modulatory properties of mesenchymal stem cells by targeting TAK1-binding protein 2. J. Biol. Chem. 288: 11074-11079. http://dx.doi.org/10.1074/jbc.M112.414862

\section{Supplementary material}

Table S1. Target genes of differently expressed microRNA.

Genetics and Molecular Research 15 (3): gmr.15038631 